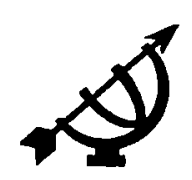

\title{
Personal and behavioural variables and the self-regulated learning abilities of African learners
}

\author{
J.L. de K. Monteith \\ Graduate School of Education \\ Potchefstroom University for CHE \\ POTCHEFSTROOM \\ E-mail: dopjm@puknet.puk.ac.za
}

\begin{abstract}
Personal and behavioural variables and the self-regulated learning abilities of African learners

Accepting responsibility for one's learning is not only an important variable that influences effective learning, but is also one of the main characteristics of selfregulated learning. Self-regulated learners know how to use their knowledge of the personal (e.g. goal setting) and behavioural variables (e.g. learning strategies) that affect learning to their advantage. Within the context of self-regulated learning, much emphasis is placed on the role of the self and self-knowledge. In this article self-regulated learning and the role of the self are evaluated from $a$ Christian perspective.

In the research underlying this article it was established that, although there were some statistically significant relationships between some personal and behovioural variables and the self-regulated learning abilities of African students, these relationships were not of practical significance. The results of the research led to the conclusion that the subjects lacked knowledge of themselves as learners.
\end{abstract}

\section{Background}

The poor academic achievement of African learners as reflected in the yearly matric results has been contributed to, inter alia, learners who neither study nor feel responsible for their failures at school (Mthembu, 1993:2), while successes in the 1996 matric exams were contributed to high levels of co-operation between parents, principals, teachers and leamers, disciplined determination, and confidence, committed teachers and a culture of teaching and learning (Anon., 
1997a) and learners who are active participants in the learning process (Henning, 1997:14).

Feeling responsible for one's successes and failures is an important prerequisite for effective learning and success at school. The importance of taking responsibility for one's learning is borne out by Curriculum 2005 which, through a system of Outcomes-based Education (OBE), has as some of its aims learners who take more responsibility for their own learning, learners who are able to make appropriate learning decisions, who are independent in their learning and thinking, are self-assessing, and organize and manage themselves and their activities (Anon., 1997b:18, 24)

OBE thus considers taking responsibility for one's own learning, and developing into independent or autonomous learners as important educational goals. Taking responsibility for one's own learning is one of the important characteristics of self-regulated learners (Zimmerman, 1990:4).

\subsection{Self-regulated learning}

Self-regulated learners are defined as learners who are metacognitively, motivationally, and behaviourally active participants in their own learning (Zimmerman, 1989:329). Metacognitively, they set learning goals, plan how to attain these goals, monitor and evaluate their progress at various stages during the process of goal attainment. Motivationally, they report high self-efficacy, intrinsic task interest, and perceive themselves as competent and autonomous. Behaviourally, they are self-starters who display extraordinary effort and persistence during learning. They select, structure, and understand their environment and improve it through the use of various strategies (Zimmerman, 1990:5)

Self-regulated learners are independent learners in that they personally initiate and direct their own efforts to acquire knowledge and skills rather than rely on other people such as their parents or teachers to persuade them to do their schoolwork (Tuckman, 1990:292). They approach their tasks with confidence, diligence and resourcefulness. They are aware when or when not they know a fact or possess the skills required to perform particular tasks. They proactively look for information when needed and take the necessary steps to assimilate such information. When they encounter obstacles such as poor study conditions and poor teachers they find ways to succeed. They view learning and studying as a systematic and controllable process, and accept greater responsibility for their learning and studying outcomes (Zimmerman, 1990:4)

From a Christian perspective one should keep in mind that man, i.c. the learner, is the image-bearer of God. Being an image-bearer means that the learner is accountable and responsible for his/her actions (Van Brummelen, 1990:140), thus 
for his ${ }^{1}$ learning outcomes. The leamer should therefore always be aware that in taking responsibility for his own learning, such a responsibility will always be a responsibility and accountability towards God; a responsibility for carrying out his cultural mandate and accountability for the way in which such responsibility is carried out.

\subsection{The assumptions underlying self-regulated learning}

The social cognitive view of self-regulated learning postulates four assumptions that underlie self-regulated learning, viz. triadic reciprocality, self-efficacy, the sub-processes of self-observation, self-judgement or self-evaluation and selfreaction and the state of self-regulation.

\section{- Triadic reciprocality}

Triadic reciprocality refers to the assumption that self-regulated learning is the result of the reciprocal influence among three sets of variables or determinants, i.e. personal, behavioural, and environmental variables or determinants (Bandura, 1986:23). Personal determinants, such as learners' knowledge of the variables that affect their learning, metacognitive processes, self-efficacy beliefs, and the learning goals they set, are assumed to be influenced by both behavioural variables, such as the learning strategies they use, and environmental events in a reciprocal way during learning. Reciprocality, though, does not mean equality in strength. Environmental variables may be stronger than behavioural or personal variables in certain contexts or situations, or vice versa. For example in schools with large classes (i.e. a high teacher-student ratio), a highly structured curriculum or with teachers who are very directive, many forms of self-regulation, i.e. such as learners taking initiative to complete learning tasks, may be inhibited. Self-regulated learning thus occurs to the degree that a learner can use personal processes to strategically regulate his leaming and the immediate learning environment (Zimmerman, 1989:330).

\section{- Self-efficacy beliefs}

Self-regulated learning depends upon a learner's self-efficacy beliefs. Selfefficacy refers to one's personal beliefs that one can successfully perform the activities required to obtain one's goals (Bandura, 1986:391). Self-efficacy is not concerned with the skills one has, but with the judgement of what one can do or achieve with whatever skills one possesses (Bandura, 1986:391).

1 The male form is used for mere simplicity and not for reasons of ideological bias Choose she or her if so preferred 
Personal and behovioural variables and self-reguloted learning abllities of African learners

High self-efficacy stimulates effort and persistence when problems are encountered, while low self-efficacy leads to doubt, avoidance behaviour and lack of effort (Schunk, 1988:8). Schunk (1985:208) reports that learners who have a high sense of self-efficacy for learning expend greater effort and persist longer when studying and achieve better results when leaming than those leamers who doubt their capabilities.

\section{- Self-regulation involves sub-processes}

A third assumption underlying self-regulated learning is that self-regulation involves a set of sub-processes that must be developed and mobilized for effective learning (Bandura, 1986:336). To self-regulate learning one has to observe or monitor the progress being made towards a learning goal (selfobservation), evaluate such progress (self-judgement), and if necessary adjust one's learning (self-reaction) (Bandura, 1986:336).

To learn effectively one continuously has to be aware of how one is progressing on the way to goal attainment. To be aware of such progress, for example, requires a learner to set a learning goal, choose a learning strategy to attain such a goal and to monitor (i.e. self-observation) his progress continuously to determine whether he is still on track towards goal attainment.

Self-judgement refers to evaluating the progress one is making or not. Learners are capable of judging the progress they are making on the basis of the goals they have set for themselves (Bandura, 1985:270). The goals become the standards which are used as criteria to determine whether they are making progress or not. The discrepancy between the level of achievement and the goal set gives an indication whether progress is being made, how much progress has been made, or what should be done to make progress.

If a learner judges that no progress is being made because of an unsuitable learning strategy, the learner can self-react by replacing such a learning strategy with another.

\section{- Self-regulated learning not an absolute state of functioning}

A fourth important assumption underlying self-regulated learning is that selfregulated learning is never an absolute state of functioning but that it varies in degree. Self-regulation depends on the degree to which the learner can exert strategic control over each of the personal, environmental and behavioural variables that affect learning (Zimmerman, 1989:332). Only when a learner can exert sufficient control over these variables can his/her learning be described as self-regulated. Self-regulated learning thus requires sufficient freedom to regulate one's own learning. 


\subsection{The role of the self and self-knowledge}

If self-regulated learning and the variables that affect self-regulated learning are analysed, it becomes clear that knowledge of the self as a learner is a basic prerequisite for self-regulation. Knowing how one learns is concerned with learners' awareness of themselves as learners, that is, how reflective they are about themselves as learners and how tuned in they are to themselves as learners. Successful learners know which learning style they prefer, which subjects are easier or more difficult for them to learn, and what the best and worst times of the day are for them to study (Weinstein \& Meyer, 1991:19). Without such knowledge learners will not be able to manage and take responsibility for their learning activities. Therefore the better the learner knows himself (i.e. selfknowledge) as a learner and the variables that affect his learning, the more effective learning will be.

In attaching such importance to the self one should refrain from the liberalist view of mankind which stresses the inalienable rights of the individual opposed to society, with the individual who holds the future in his/her hands and not society (Van der Walt, 1994:234). With the focus on self-regulation in this article one should further refrain from viewing self-regulation from a humanistic perspective with its excessive and, from a Christian perspective, unhealthy emphasis on selfaggrandisement or self-gratification. From a Christian perspective the learner is seen as a steward who should regard all things, including his own gifts (inter alia his abilities) as a trust to be exercised for the enrichment of the world in submission to God whose world this is (Fowler, 1990:85)

As steward and image-bearer of God, endowed with special gifts to serve God and his fellow human beings, a learner has a responsibility and is accountable to God to reflect God in his life through exercising his freedom and abilities by ruling over His creation (Van Brummelen, 1990:139/40). The teacher has a special task in helping leamers to understand their gifts better and to help them develop their gifts as he has to help the learner to image God through a better knowledge of himself as a learner and of his learning capabilities.

However, valid self-knowledge is only possible through a thorough knowledge of God (Van der Walt, 1994:173; Spykman, 1992:201). Therefore, in order to acquire valid and true knowledge of himself as a learner, the learner first has to seek and acquire knowledge of God. The learner should therefore always acknowledge that just as his knowledge of God will be imperfect (but still sufficient for his salvation), his knowledge of himself as a leamer will be imperfect. The learner can therefore never be completely autonomous and selfregulated, because he is only granted a relative independence, being always fully dependent on God (Spykman, 1992:160). 


\subsection{Aim of this article}

To qualify as being self-regulated, leamers must use specific (learning) strategies to achieve their academic goals on the basis of self-efficacy perceptions (Zimmerman, 1989:329). The aim of the research underlying this article was to determine the relationship between personal variables, such as goal setting and self-efficacy, and behavioural variables, such as learning strategies, and the selfregulated learning abilities of African learners.

\section{Method}

\section{- Subjects}

All the grade 9 Vatsonga learners $(\mathrm{N}=2771)$ in the secondary schools in the Ritavi 1 and 2 circuits of the Northem Province formed the population for this study. A cluster sample of seven classes, giving a sample of 374 subjects, was drawn at random from this population.

\section{- Instruments}

Apart from a biographical questionnaire designed to obtain data on the subjects' age, sex, academic goals, family and home related characteristics, the LASSI-HS (Learning and Study Strategies Inventory-High School Version) developed by Weinstein and Palmer (1990), the MSLQ (Motivated Strategies for Learning Questionnaire) as used by Pintrich and De Groot (1990) and the CMSES (Children's Multidimensional Self-Efficacy Scales) developed by Bandura (1989) were used. All three these instruments were adapted to South African circumstances

The Leaming and Study Strategies Inventory-High School Version is an assessment tool consisting of 76 items, designed to measure learners' use of learning and study strategies and methods at high school level. Learners respond to the items on a 5-point Likert-type scale (ranging from $1=$ "not at all like me" to 5 = "very much like me").

The LASSI-HS consists of the following ten subscales: attitude, motivation, time management, anxiety, concentration, information processing, selecting main ideas, using study aids, self-testing, and test strategies.

Only the cognitive strategy use, self-regulation, and intrinsic value sub-scales of the Motivated Strategies for Learning Questionnaire were used. Learners respond to the items on a 7-point Likert scale (ranging from 1 = "not at all true of me" to 7 = "very true of me").

The Children's Multidimensional Self-Efficacy Scales, consisting of 40 items, were used to assess self-efficacy. These items were categorized into the 
following aspects: self-efficacy in enlisting social resources, self-efficacy for academic achievement, self-efficacy for self-regulated leaming, self-assertive self-efficacy and self-efficacy for enlisting parental and community support. For each item learners rate their perceived self-efficacy on a 7-point Likert scale (ranging from $1=$ "not well at all" to $7=$ "very well") in terms of their behaviour in class.

\section{Results}

Data on the following variables were obtained by applying these instruments: age, attitude towards leaming, motivation, time management, anxiety, concentration, information processing, selecting main ideas, study aids, selftesting, test-taking strategies, self-efficacy for academic achievement, selfefficacy for self-regulated learning, self-efficacy for social resources, self-efficacy for enlisting parents and community support, intrinsic value, strategy use, socioeconomic status, living space, goal setting, home and teacher support. Selfregulated learning was used as dependent variable.

Multiple regression analysis revealed that these variables explained 54,03 percent $\left(R^{2}=0,5403 ; R^{2}=0,4588\right)$ of the variance in self-regulated learning. By using the $\mathrm{BMDP}-9 \mathrm{R}$ procedure with method $=\mathrm{RSQ}$ the best subset of independent variables i.e., the smallest subset of variables that contributes the most to $R^{2}$, was identified by applying the $\mathrm{Cp}$ criterion. This subset of variables was then subjected to a further mulțiple regression analysis to determine the contribution of each of the variables to $R^{2}$ (see table 1 ).

An analysis of table 1 reveals that the variables comprising the best subset of variables together explain 40,62 percent $\left(R^{2}=0,4062 ; \quad R_{a}^{2}=0,3844\right)$ of the variance in self-regulated learning.

Cohen's (1977) effect sizes were calculated in all instances to determine the educational or practical significance of relationships.

An analysis of table 1 reveals that only two personal variables, viz. attitude towards learning and intrinsic value, and only four behavioural variables i.e. selecting main ideas, concentration, using study aids and strategy use, were included in the best subset of variables. Although each of these variables makes a statistically significant contribution to $\mathrm{R}^{2}$, these contributions are of little educational significance because of the small effect sizes.

On the basis of their self-regulation scores the subjects were divided into subgroups ranging from low on self-regulation to high on self-regulation. One-way ANOVA's with Tukey's post hoc comparison were then calculated to determine how leamers who were more self-regulated differed from those learners who 
were less self-regulated with relation to each of the personal and behavioural variables included in the best subset of variables.

\section{Table 1: The collective and individual contribution of the variables in the best subset of variables to $R^{2}$. Criterion: self-regulated learning.}

$\mathrm{R}^{2}=0,4062\left(\mathrm{R}_{\mathrm{a}}^{2}=0,3844\right) ; \mathrm{C}=3,21$

\begin{tabular}{|c|c|c|c|c|}
\hline Variables & $\begin{array}{l}\text { Regression } \\
\text { coefficient }\end{array}$ & $\begin{array}{l}\text { Contribution } \\
\text { to } \mathbf{R}^{2}\end{array}$ & F-value & $\begin{array}{l}\text { Effect } \\
\text { size } \\
\left(f^{2}\right)\end{array}$ \\
\hline $\begin{array}{l}\text { Attitude } \\
\text { Concentration } \\
\text { Selecting main ideas } \\
\text { Study aids } \\
\text { Self-efficacy for enlisting } \\
\text { parents and community } \\
\text { support } \\
\text { Intrinsic value } \\
\text { Strategy use } \\
\text { Goal setting }\end{array}$ & $\begin{array}{l}0,1996 \\
0,2533 \\
0,4163 \\
0,3012 \\
\\
0,1588 \\
\\
0,1653 \\
0,1346 \\
0,0038\end{array}$ & $\begin{array}{l}0,0116 \\
0,0189 \\
0,0214 \\
0,0287 \\
\\
0,0083 \\
\\
\\
0,0238 \\
0,0176 \\
0,0071\end{array}$ & $\begin{array}{c}4,46^{*} \\
7,28^{* *} \\
8,23^{* *} \\
11,04^{* *} \\
3,2 \\
\\
9,14^{* *} \\
6,75^{* *} \\
2,74\end{array}$ & $\begin{array}{l}0,02 \\
0,03 \\
0,04 \\
0,05 \\
0,01 \\
\\
0,04 \\
0,03 \\
0,01\end{array}$ \\
\hline & $\begin{array}{r}{ }^{*} \mathrm{p}<0,05 \\
{ }^{* *} \mathrm{p}<0,01\end{array}$ & $\begin{array}{l}\text { Small effect } \\
\text { Medium effect } \\
\text { Large effect }\end{array}$ & & $\begin{array}{l}=0,02 \\
=0,15 \\
=0,35\end{array}$ \\
\hline
\end{tabular}

The ANOVA's revealed a statistically significant difference in both the personal variables attitude towards learning $\mathrm{F}(4,328)=3,3, \mathrm{p}<0,05 ; \mathrm{f}=0,04$ and intrinsic value $\mathrm{F}(4,328)=11,7 \mathrm{p}<0,05 ; \mathrm{f}=0,14$ between more self-regulated and less selfregulated learners. The ANOVA's also revealed that there were statistically significant differences between learners who were more self-regulated and those learners who were less self-regulated with reference to the behavioural variables selecting main ideas $F(3,329)=10,20 ; p<0,05 ; f=0,09$, concentration $F(4,328)=3,49 ; \quad p<0,05 ; \quad f=0,05$, using study aids $F(4,328)=5,99 ; \quad p<0,05$; $\mathrm{f}=0,08$ and strategy use $\mathrm{F}(4,328)=27,88 ; \mathrm{p}<0,05 ; \mathrm{f}=0,34$.

Tukey's post hoc comparison revealed that learners who were more selfregulated had a more positive attitude towards learning, valued leaming more than learners who were less self-regulated, were better at selecting main ideas, concentrated better when learning and used more study aids than learners who were less self-regulated. The effect sizes ranging from $(f=0,04)$ to $(f=0,14)$ were 
small, implying that the differences are of little educational or practical significance.

With reference to strategy use the effect size $(\mathrm{f}=0,34)$ is large, therefore the difference between more self-regulated and less self-regulated learners concerning the use of learning strategies is of large educational significance. It can therefore be concluded that strategy use is an important variable that does not only characterize self-regulated learners, but also differentiate between learners who are more self-regulated and learners who are less self-regulated.

An analysis of the mean scores on the self-efficacy scales revealed that the subjects' mean scores were extremely high. For example the mean score for selfefficacy for self-regulated learning was 67 (maximum $=77 ; \mathrm{SD}=9$ ) and for selfefficacy for academic achievement 54 (maximum $=63 ; \mathrm{SD}=8$ ). The standard deviations indicate a large variation in scores. It thus seems as if the subjects may lack realistic knowledge of themselves as learners

\section{Discussion}

The educational or practical significance of the relation between strategy use and self-regulated learning indicates that the use of learning strategies is an important variable that differentiates between more and less self-regulated learners. It can therefore be concluded that if learners can be convinced of the value of learning strategies and be taught to use a variety of learning strategies, their ability to selfregulate their learning can be improved - resulting in higher academic achievement (Pintrich \& De Groot, 1990:3; Pressley et al., 1989:858)

Self-knowledge results from self-observation and self-appraisal, important components of self-regulated learning (Ertmer \& Newby, 1996:3). If learners lack realistic self-knowledge they will be insensitive to their limitations as learners, will not know when they set unrealistic goals, use inappropriate learning strategies, etc. and will therefore neither evaluate their progress nor make corrections when they are not on-line to attain their learning goals. They will, therefore, not succeed in school

The lack of self-knowledge may be contributed to inappropriate goal setting and large classes.

Goal setting, especially with reference to personal or self-set goals, implies competition. Africans traditionally are communally orientated and therefore shy away from individualistic competition (Van der Walt, 1994:205). Self-set goals require initiative and imply accepting responsibility for attaining them. Such initiative and acceptance of responsibility may be a problem in a culture which sets store on communal responsibility and where personal initiative (Van der 
Personal and behovioural variables and self-regulated learning abllities of African learners

Walt, 1997:61) or self-enhancement (Kurman \& Srinam, 1997:442) is not highly regarded.

Within African culture, group pressure and conformity to group norms exert a strong influence on learners not to perform better than the norms of the group to whom they belong (Van der Walt, 1994:207). Not many learners are therefore willing to rise above these norms. Those who do (e.g. high achievers) experience a lack of acceptance in their culture (Wallace Adams, 1996:315), risk being rejected and receive no support from the group (Van der Walt, 1997:62).

Conceptions of the self may also serve as an explanation for an unwillingness to rise above the group. Conceptions of the self differentiate into individualistic and collectivist conceptions. Cultural groups with an individualistic view of the self regard the self as rooted in the realm of an awareness that is intrinsic, private, and unique to the person - a view of the self that gives a sense of distinctiveness or separateness from others. Personal independence, self-determination, and selfcontrol in setting and achieving personal goals, aspirations, and preferences are valued highly. Such individualistic perceptions of the self are associated with Western cultures (Mpofu, 1995).

African societies are among the most communal (Van der Walt, 1994:205) or collectivist in their view of the self (Mpofu, 1995). Collectivist cultures foster a sense of the self that emphasizes members' public spiritedness rather than individual privacy, the common as opposed to the unique. A person's selfidentity is seen in terms of his or her perceived connectedness with significant others (e.g. the family or clan) who both constitute and validate the individual's sense of self-hood. Goals, aspirations, and preferences are perceived in terms of how they promote an individual's expression of belonging and how they advance the goals of the collective (Mpofu, 1995).

The large classes (the subjects for this study came from classes that ranged from 38 to 70 students per class) characteristic of black schools may also have an effect. Large classes and a wide range of learner ability within one class cause difficulties which most teachers solve by means of rigid and didactic teaching styles that promote rote learning, with not much attention being paid to the development of higher order cognitive skills (Wallace Adams, 1996:315). As the system of testing and examination supports this way of teaching (Wallace Adams, 1996:316), higher cognitive skills such as metacognitive awareness do not develop. Consequently, learners lack self-awareness which may negatively affect their ability to set realistic goals and to develop realistic self-efficacy beliefs.

Large classes may also reduce the role of the learner to that of a passive learner because all teaching activity focuses on the teacher. The teacher not only promotes rote learning, but also sets the goals to be attained and determines the 
method of assessment to evaluate goal attainment. This state of affairs contravenes a defining condition for self-regulation, i.e. the availability of choice and self-control of learners. Inferences about leamers' self-regulated learning capabilities can not be made if learners do not have options available or can not control their method of studying (Zimmerman, 1994). The learners' degree of self-regulation is assumed to be determined by the degree to which they can exert strategic control over the personal, behavioural and environmental variables that affect their learning (Zimmerman, 1989).

If educational practice does not allow learners the freedom of choice and control over their own learning, or to develop their abilities to observe, monitor or evaluate themselves while learning, they will be insensitive to their limitations as leamers. They will also not know when they set unrealistic goals, use inappropriate learning strategies, etc. They will neither evaluate their progress nor make corrections when they are not on course to attain their learning goals. They will therefore, neither succeed in school, nor develop their capabilities to self-regulate their learning.

Self-regulated learners exercise a large degree of control over the attainment of their goals (Schunk, 1989:83). The question that begs answering is whether African learners can exercise control over the attainment of their goals in a system of large classes that promotes rote learning and subservience (Naudé \& Van der Westhuizen, 1996:160).

\section{In conclusion}

Within a culture that inhibits the setting of academic goals that exceed those of the group, and large classes that reduce the role of the learner to that of subservience, a learner is deprived of the opportunity to develop adequate self-knowledge. Self-knowledge is an important prerequisite for accepting responsibility for one's actions and for self-regulated learning. The question that begs an answer is whether a system of education that allows such a practice is conducive for providing the learner, as steward and image bearer, the opportunities to develop his gifts in a way to fulfil his calling. An educational system which does not enable the learner to develop a better understanding of and the capability to use his particular gifts to their fullest, can thus - from a Christian perspective - be considered a failure.

\section{References}

ANON. 1997a. Matric begins to beat the race barriers of the past. Sunday Times, January 5

ANON. 1997b. Outcomes based education in South Africa. Background information for educators. Department of Education March 1997.

BANDURA, A. 1985. Cognitive learning theory. New York : Holt, Rinehart \& Winston 
Personal and behovioural variables and self-regulated learning abilities of African learners

BANDURA, A. 1986. Social foundations of thought and action: a social cognitive theory Englewood Cliffs, N.J. : Prentice-Hall

BANDURA, A 1989. Multidimensional scales of perceived self-efficacy. Unpublished test Stanford University, Stanford, CA

COHEN, J. 1977 Statistical power analysis for the behavioural sciences Orlando, Fla. Academic Press

ERTMER, P A. \& NEWBY, T J. 1996. The expert learner: strategic, self-regulated, and reflective. Instructional Science, 24:1-24

FOWLER, S 1990. Educated paupers or prosperous stewards? (In Fowler, S., Van Brummelen, H.W. \& Van Dyk, J. Christian schooling: education for freedom. Potchefstroom : IRS. p 81-104)

HENNING, M. 1997. Teach our children well from the start and it will pay off later Sunday Times.14, January 11

KURMAN, J. \& SRINAM, N 1997. Self-enhancement, generality of self-evaluation, and affectivity in Israel and Singapore Journal of Cross-Cultural Psychology, 28(4) 421441.

MPOFU, E. 1995. Exploring the self-concept in African culture Journal of Genetic Psychology, 155(3) 341-354

MTHEMBU, S. 1993. Learners on the rampage. Sowetan, February 19.

NAUDÉ, G.N. \& VAN DER WESTHUIZEN, G J. 1996. Teaching thinking: empowering teachers for cognive education (In Engelbrecht, P., Kriegler, S.M. \& Booysen, M I eds. Perspectives on learning difficulties. International concerns and South African realities Pretoria : Van Schaik. p. 159-174.)

PINTRICH, P R. \& DE GROOT, E.V. 1990 Motivation and self-regulated learning components of classroom academic performance. Journal of Educational Psychology, 82:33-40

PRESSLEY, M., BORKOWSKI, J.G \& SCHNEIDER, W. 1989 Good information processing: What it is and how education can promote it International Journal of Eduational Research, 13:857-867.

SCHUNK, D.H. 1985. Self-efficacy and classroom learning. Psychology in the Schools, 22:208-215.

SCHUNK, D.H 1988 Perceived self-efficacy and related social cognitive processes as predictors of learner academic performances (Paper presented at a symposium entitled "Self-regulated learning processes: emerging evidence of a key role in learner motivation and achievement" at the annual meeting of the American Educational Research Association, New Orleans)

SPYKMAN, G.J. 1992 Reformational theology A new paradigm for doing dogmatics. Grand Rapids, Mich. : Eerdmans

TUCKMAN, B.W. 1990 Group versus goal-setting effects on the self-regulated performance of students differing in self-efficacy Journal of Experimental Education, 58(4) 291298

VAN BRUMMELEN, H.W 1990 Imaging God in learning. (In Fowler, S., Van Brummelen, H.W \& Van Dyk, J. Christian schooling: education for freedom Potchefstroom : IRS. p 139-154.)

VAN DER WALT, B J. 1994. The liberating message. A Christian worldview for Africa Potchefstroom : PU for CHE. (Scientific Contributions of the PU for CHE. Series F Institute for Reformational Studies, F3: Collections, No. 44.)

VAN DER WALT, B J. 1997. Being human in a Christian perspective. Potchefstroom : PU for CHE (Scientific Contributions of the PU for CHE Series F2: Brochures of the Institute for Reformational Studies, $\mathrm{Nr}$ 68.) 
WALLACE ADAMS, B. 1996 A consideration of key factors contributing to underachievers in South African schools (In Engelbrecht, P., Kriegler, S M \& Booysen, M.I eds Perspectives on learning difficulties International concerns and South African realities Pretoria : Van Schaik. p. 312-323.)

WEINSTEIN, C.E. \& MEYER, DK. 1991. Cognitive learning stragtegies and college teaching. New Directions for Teaching and Learning, 45.15-26.

WEINSTEIN, C.E. \& PALMER, DR 1990. LASSI-HS user's manual. Austin : University of Texas.

ZIMMERMAN, B J. 1989. A social cognitive view of self-regulated academic learning Joumal of Educational Psychology, 81(3):329-339

ZIMMERMAN, B.J. 1990. Self-regulated learning and academic achievement: an overview Educational Psychologist, 25(1):3-17

ZIMMERMAN, B.J. 1994. Dimensions of academic self-regulation: A conceptual framework for education. (In Schunk, D.H \& Zimmerman, B J., eds Self-regulation of learning and performance Issues and educational applications Hillsdale, N.J Lawrence Erlbaum. p 3-21.) 